\title{
Debugging: Is Routine Antimicrobial Prophylaxis Indicated in Medical Thoracoscopy?
}

\author{
Jane A. Shaw Coenraad F.N. Koegelenberg \\ Division of Pulmonology, Department of Medicine, Stellenbosch University and Tygerberg Academic Hospital, \\ Cape Town, South Africa
}

Endoscopic pleuroscopy has evolved over more than a century from a procedure using a modified cystoscope with a candle for a light source, to the technologically advanced video-assisted thoracic surgery (VATS) [1]. While the "father of thoracoscopy," a Swedish internist named Hans Christian Jacobaeus, primarily used the technique for intrapleural pneumolysis in tuberculosis patients, he also advocated its use for diagnostic purposes in a range of both pleural and parenchymal disorders $[1,2]$. His vision proved true, and today after numerous innovations in instrumentation, thoracoscopic techniques are invaluable to both thoracic surgeons and pulmonary physicians.

Surgical or open thoracotomy is accompanied by an inherent risk of postoperative infection - in the form of an empyema, pneumonia, or a surgical site infection (SSI) [3]. Surgical society guidelines appear reasonably wellsupported by the literature in their recommendations that antimicrobial prophylaxis be administered in open thoracic procedures [3]. The overall rate of infection associated with thoracic surgery is quoted as $0.76-2.04 \%$, with rates of pneumonia from 3 to $24 \%$, and empyema from 0 to $7 \%$, when antimicrobial prophylaxis is administered [3]. The rate of SSI may be as high as $14 \%$ without antimicrobial prophylaxis and drops to $0.42-4.0 \%$ when prophylaxis is administered [3].

\section{KARGER}

(C) 2017 S. Karger AG, Basel

E-Mail karger@karger.com

www.karger.com/res
The rate of SSI with VATS, which is less invasive than open thoracic surgery, is lower, ranging from 1.7 to $5.5 \%$, and for medical thoracoscopy it is even lower $[4,5]$. Empyema occurs in $1.9-2.7 \%$ and SSI around 3\% of cases following medical thoracoscopy without antimicrobial prophylaxis [6-9].

Whereas the strength of evidence for antimicrobial prophylaxis in open thoracic surgery patients is good (level A), this could not be further from the truth for thoracoscopy. Some evidence shows that antimicrobial prophylaxis is not indicated for intercostal drain insertion unless in the setting of trauma [10]. With a paucity of high-quality evidence, there is significant heterogeneity of practice worldwide with regard to antimicrobial prophylaxis for medical thoracoscopy. Even current guidelines, which reasonably recommend routine prophylaxis only in patients with risk factors such as asplenia, prosthetic heart valves, and previous endocarditis, preface their recommendations with the note that their document is drafted solely on the basis of expert opinion [11].

Considering the population of patients who are likely to undergo such a procedure - patients with malignancy, immunocompromised, who have had repeated pleural aspirations or even biopsies - it seems reasonable to hypothesise that the risk of post-procedural infection would

Coenraad F.N. Koegelenberg

Division of Pulmonology, Department of Medicine Stellenbosch University and Tygerberg Academic Hospital PO Box 241, Cape Town 8000 (South Africa)

E-Mail coeniefn@sun.ac.za 
be high. The sterile pleural space may have been repeatedly compromised, and adhesions or anatomical abnormalities of the pleura itself may provide a potentially microbe-friendly environment.

It is also clear that in the current climate of rapidly emerging highly resistant microbes, every physician has a duty to enforce strict antibiotic stewardship, making evidence-based decisions and justifying every dose of antimicrobial agent prescribed. The question of prophylactic use of antimicrobials becomes even more important and controversial in this light; and it must be answered.

In the present edition of Respiration, Dhooria and colleagues have made admirable inroads into gathering the evidence that we need [12]. They recruited patients who underwent diagnostic medical thoracoscopy without recent exposure to antimicrobials, randomised them to a single dose of $2 \mathrm{~g}$ intravenous cefazolin (a choice based on a surgical guideline) or placebo infusion prior to thoracoscopy, and analysed whether there was a significant difference in the rate of empyema or SSI between the groups. This, they did not find.

The overall incidence of infectious complications among their 100 participants was $10 \%$, which seems high until one considers that many of their procedures were prolonged by the presence of dense pleural adhesions. A rate of $6 \%$ for empyema and $4 \%$ for SSI is higher than previously reported rates for medical thoracoscopy, but this remains comparable to the rates obtained for VATS, and far lower than the infection rates of open thoracic surgery without antimicrobial prophylaxis $[4,6]$.

The baseline characteristics and risk factors for infection, such as diabetes and chronic kidney disease, did not differ between the groups, and specifically were not different between patients who developed infection and those who did not [12]. Two deaths occurred in the study and appear to have been unrelated to infection.

Whilst the numbers in the study were small, it remains to the best of our knowledge the only prospective study to address this particular question. Moreover, at the very least, it clarifies the fact that the surgical guidelines regarding antimicrobial prophylaxis simply cannot be considered "coverall" guidelines for every thoracic procedure. Clearly, only large prospective multicentre studies will ultimately assist us in debugging the issues around antimicrobial prophylaxis and medical thoracoscopy.

\section{References}

1 Moisiuc F, Colt H: Thoracoscopy: origins revisited. Respiration 2007;74:344-355.

2 Lee P CH: Pleuroscopy in 2013. Clin Chest Med 2013;34:81-91.

3 Bratzler D, Dellinger E, Olsen K, et al: Clinical practice guidelines for antimicrobial prophylaxis in surgery. Am J Heal Syst Pharm 2013; 70:195-283.

4 Rovera F, Imperatori A, Militello P, et al: Infections in 346 consecutive video-assisted thoracoscopic procedures. Surg Infect 2003;4: 45-51.

5 Imperatori A, Rovera F, Rotolo N, Nardecchia E, Conti V, Dominioni L: Prospective study of infection risk factors in 988 lung resections. Surg Infect 2006;7(suppl 2):S57-S60.
6 Viskum K, Enk B: Complications of thoracoscopy. Poumon Coeur 1981;37:25-28.

7 Viallat J, Rey F, Astoul P, Boutin C: Thoracoscopic talc poudrage pleurodesis for malignant effusions. A review of 360 cases. Chest 1996;110:1387-1393.

8 de Campos J, Vargas F, de Campos Werebe E, et al: Thoracoscopy talc poudrage: a 15 -year experience. Chest 2001;119:801-806.

9 Rodríguez-Panadero F: Medical thoracoscopy. Respiration 2008;76:363-372.
10 Fallon WJ, Wears R: Prophylactic antibiotics for the prevention of infectious complications including empyema following tube thoracostomy for trauma: results of meta-analysis. J Trauma 1992;33:110-116.

11 Rahman NM, Ali NJ, Brown G, et al: Local anaesthetic thoracoscopy: British Thoracic Society Pleural Disease Guideline 2010. Tho$\operatorname{rax} 2010 ; 65$ (suppl 2):ii54-ii60.

12 Dhooria S, Sehgal IS, Prasad KT, et al: A randomized trial of antimicrobial prophylaxis in patients undergoing medical thoracoscopy (APT). Respiration 2017;94:207-215. 